\title{
O Barata Ribeiro 200 com pós-escrito de Yvonne Maggie e comentários de Anthony Leeds
}

The apartment building at 200, Barata Ribeiro street

\section{Gilberto Velho e Yvonne Maggie}

\section{(2) OpenEdition}

12 Journals

Edição electrónica

URL: http://journals.openedition.org/aa/528

DOI: 10.4000/aa.528

ISSN: 2357-738X

Editora

Programa de Pós-Graduação em Antropologia Social (UnB)

\section{Edição impressa}

Data de publição: 31 dezembro 2013

Paginação: 19-36

ISSN: 0102-4302

\section{Refêrencia eletrónica}

Gilberto Velho e Yvonne Maggie, «O Barata Ribeiro 200 com pós-escrito de Yvonne Maggie e

comentários de Anthony Leeds», Anuário Antropológico [Online], v.38 n.2 | 2013, posto online no dia 01 fevereiro 2014, consultado o 28 abril 2021. URL: http://journals.openedition.org/aa/528 ; DOI: https:// doi.org/10.4000/aa.528

Este documento foi criado de forma automática no dia 28 abril 2021.

\section{cc)}

Anuário Antropológico is licensed under a Creative Commons Atribuição-Uso Não-Comercial-Proibição de realização de Obras Derivadas 4.0 International. 


\title{
O Barata Ribeiro 200 com pós- escrito de Yvonne Maggie e comentários de Anthony Leeds
}

The apartment building at 200, Barata Ribeiro street

\author{
Gilberto Velho e Yvonne Maggie
}

\section{NOTA DO EDITOR}

Recebido em 23/09/2013

Aceito em 25/09/2013

\section{Apresentação ${ }^{1}$}

1 O Barata Ribeiro 200 (Edifício Richard) é um dos prédios mais notórios do Rio de Janeiro. Esta sua "fama" se deve à sua presença contínua na crônica policial e nos noticiários escandalosos dos jornais e como símbolo de tudo o que possa haver de precário em termos de "estilo de vida urbano". Problema permanente para as autoridades e escândalo para os arquitetos, o Barata Ribeiro 200 revela alguns aspectos interessantes da "boa consciência" das autoridades e da ideologia de camadas médias urbanas.

O prédio está situado na Rua Barata Ribeiro, entre as ruas General Azevedo Pimentel e Praça Cardeal Arcoverde. Esta é a parte de Copacabana que foi primordialmente urbanizada. O ponto de referência original era o Copacabana Palace, junto ao qual desenvolveram-se intenso comércio e especulação imobiliária. Com o crescimento do bairro, esta parte passou a ser o centro de vida noturna da Zona Sul. Hotéis, bares, boates, "inferninhos" surgiram em profusão ao lado de grande número de prédios residenciais. Em poucos anos todos os terrenos foram ocupados. A ocupação final pode ser estabelecida no grande "boom" imobiliário de meados da década de 50 (época de 
construção do 200). Já nessa época, no entanto, outras áreas de Copacabana (posto 4, 5 , 6), algum tempo depois, Ipanema e Leblon já passavam também por fase de alta especulação imobiliária, ativa construção civil e incremento do comércio. Pode-se dizer, no entanto, que estas áreas, especialmente Ipanema e Leblon, tiveram uma ocupação um pouco mais racionalizada, favorecidas por algumas medidas de urbanização com planejamento.

3 Na área do 200 (posto 1 e 2), portanto, encontramos alguns dos prédios residenciais mais antigos da Zona Sul, um tanto decadentes e maltratados, ao lado de construções mais recentes.

O Barata Ribeiro 200 começou a ser construído em 1953 e passou a ser habitado em 1957. Ocupa mais da metade do quarteirão em que está situado. Tem 12 andares com 45 apartamentos por andar, totalizando 540 unidades. Moram no prédio cerca de 2.000 pessoas. Há dois tipos de apartamentos. Em cada andar existem 30 apartamentos de sala e quarto conjugados com kitchenette com $25 \mathrm{~m}^{2}$, e 15 apartamentos de sala e quarto separados com cozinha, com $40 \mathrm{~m}^{2}$. Metade dos apartamentos dá para a Barata Ribeiro e a outra metade, de fundos, para um morro. Os apartamentos de fundos dos andares inferiores são muito escuros, estando praticamente grudados no morro. Os andares mais altos são mais claros, bem ventilados e até gozam de "nice view". 0 aluguel médio atual do apartamento conjugado é de $\mathrm{NCr} \$ 250,00$ e o do segundo tipo é de $\mathrm{NCr} \$ 350,00{ }^{2}$ É de se notar, no entanto, que a maioria dos inquilinos ainda paga aluguéis antigos (mais ou menos NCRS 10,00), bem inferiores.

5 No térreo existe um comércio variado - bares, lojas de móveis, de tapetes, farmácia etc. No primeiro andar, ao lado de apartamentos residenciais, encontram-se cabeleireiros, dentistas e outros. Existem, ainda, em outros andares várias boutiques - comércio não oficializado - e pensões. A entrada única do prédio era a entrada de serviço na planta. No entanto, os construtores do 200 (Construtora Franco-Brasileira) venderam a entrada social para uma loja. Isto é motivo de queixa dos moradores, que se consideram roubados pela construtora. $\mathrm{O}$ enorme movimento do prédio faz-se todo em torno de uma entrada pequena e estreita. Existem seis elevadores para atender a 2.000 pessoas. $O$ Edifício Richard tem um síndico eleito pelos proprietários. Ele é assessorado por um conselho de quatro membros também eleitos pelos proprietários e recebe um salário de $\mathrm{NCr} \$ 500,00$ mensais. A administradora Palmares se responsabiliza pela manutenção do edifício, dividindo responsabilidades com o síndico. Este é o responsável por todos os entendimentos entre os moradores do prédio e a Administradora, a qual deve fiscalizar. Atualmente, o síndico é um funcionário aposentado da Central do Brasil, proprietário de um apartamento conjugado no $12^{\circ}$ andar.

\section{Análise dos dados da tabela: algumas observações sobre a situação dos moradores do 200 em termos de estratificação social}

Ao iniciarmos a análise dos dados obtidos nas entrevistas, é preciso dizer que nossa amostra é, de certa forma, pouco significativa. Devido ao grande número de habitantes e à exiguidade de tempo, só nos foi possível entrevistar uma percentagem muito reduzida $(1,3 \%)$ do total dos moradores do prédio. No entanto, confrontando esses dados com outras fontes, podemos afirmar que pelo ao menos alguns destes são 
significativos para o tipo de análise que procuramos empreender e para chegarmos a algumas conclusões importantes.

7 Passemos à análise dos dados:

\section{Número de unidades habitacionais e pessoas por unidade}

8 Nas 26 unidades habitacionais visitadas vivem 64 pessoas, ou seja, 2,4 pessoas por unidade. Essa média é bastante inferior à média total do prédio $(4,3)$. Esta defasagem pode estar relacionada à precariedade de nossa amostra, mas podemos supor também que tenha havido uma resistência dos moradores em admitir o real número de habitantes em suas residências. Outra hipótese é a de que o número total de pessoas que moram no prédio seja menor do que se diz.

\section{Período de permanência no prédio}

\begin{tabular}{|l|l|}
\hline De 0 a 1 ano & 6 pessoas \\
\hline de 1 a 3 anos & 6 pessoas \\
\hline De 3 a 5 anos & 5 pessoas \\
\hline De 5 a 10 anos & 8 pessoas \\
\hline Mais de 10 anos & 4 pessoas \\
\hline
\end{tabular}

\section{Sexo e idade}

Das 64 pessoas no total de unidades visitadas, 30 eram do sexo masculino e 34 do sexo feminino. Quanto à idade, temos a seguinte variação:

\begin{tabular}{|l|l|}
\hline De 0 a 12 anos & 13 pessoas \\
\hline De 12 a 20 anos & 4 pessoas \\
\hline De 20 a 60 anos & 42 pessoas \\
\hline Mais de 60 anos & 5 pessoas \\
\hline
\end{tabular}

10 Dos 29 entrevistados, nove eram do sexo masculino e 20 do sexo feminino.

\section{Nível educacional}

\begin{tabular}{|l|l|}
\hline Analfabetos & 1 \\
\hline Alfabetizados & 2 \\
\hline
\end{tabular}




\begin{tabular}{|l|l|}
\hline Primário incompleto & 10 \\
\hline Primário completo & 4 \\
\hline Secundário incompleto & 4 \\
\hline Secundário completo & 4 \\
\hline Superior incompleto & 2 \\
\hline Superior completo & 2 \\
\hline
\end{tabular}

\section{Tamanho do apartamento}

11 Visitamos 17 apartamentos conjugados e nove de quarto e sala separados, sendo que dos 29 entrevistados, 11 eram proprietários de suas residências e 18 eram inquilinos.

\section{Origem e residência anterior}

12 Das 29 pessoas entrevistadas, 10 nasceram no Rio. Dessas 10, cinco residiam anteriormente em subúrbios, duas na Zona Sul, duas na Zona Norte e uma no Centro. Uma das entrevistadas era estrangeira e morara anteriormente na Zona Sul. Das 18 restantes, seis nasceram no estado do Rio de Janeiro, quatro em São Paulo, uma no Rio Grande do Sul, quatro em Minas Gerais, uma em Pernambuco, uma no Espírito Santo e uma no Paraná. Dessas 18, 10 vieram diretamente de outros estados para morar no 200, cinco moraram antes em subúrbios no Rio, uma na Zona Norte, uma na Zona Sul e uma no Centro da cidade. É interessante frisar que todos os naturais de outros estados já moraram em cidades antes de virem para o Rio.

\section{Ocupação e local de trabalho}

Deter-nos-emos mais neste item, na medida em que pode nos fornecer alguns dados sobre a camada ou as camadas sociais a que pertencem os moradores do Barata Ribeiro 200. De início, enunciaremos os tipos de ocupação encontrados e o número de pessoas por ocupação:

\begin{tabular}{|l|l|}
\hline Comerciários & 4 \\
\hline Donas de casa & 5 \\
\hline Funcionários públicos & 2 \\
\hline Professores & 3 \\
\hline
\end{tabular}

14 Em cada uma das ocupações que se seguem encontramos um representante: modista, farmacêutica, lavadeira, arquiteto, alfaiate, funcionária do Jóquei, vendedora de joias, costureira, médico, estudante, chofer de táxi, garota propaganda de TV e um que não 
declarou profissão. Quanto ao local de trabalho, temos: sete no Centro, três em Copacabana, um no Grajaú, um em Irajá, um na Tijuca, um na Gávea, um no Jóquei, um em Botafogo, um na Urca, um no Catete, dois não têm local de trabalho determinado, dois trabalham em casa e oito não têm local de trabalho (três aposentados e cinco donas de casa).

Verificamos que das 22 pessoas que trabalham (sem contar o estudante, as cinco donas de casa e a que não declarou profissão), 15 são empregados, sete são autônomos e nenhum é empregador. Por outro lado, a maioria dessas ocupações está relacionada com serviços urbanos, na forma de serviços ligados à administração pública, à educação, ao comércio, à diversão ou à rede hospitalar. Ainda temos que frisar que a maioria dos entrevistados se localiza nos escalões médios desses serviços (auxiliar de enfermagem, datilógrafo etc.).

Vários dos entrevistados declararam que suas rendas davam "mais ou menos para se manter", tendo muitas vezes que recorrer a outras formas para suplementá-las. $O$ atual síndico, por exemplo, funcionário público aposentado, ainda recebe uma pequena quantia para cumprir suas obrigações de síndico e duas das comerciárias costuram para fora à noite. Outro dado importante é que todos os proprietários entrevistados declararam ter conseguido comprar o apartamento (coisa que valorizam muito) com grande esforço, quer através de empréstimos públicos, quer por meio de rígida economia. A farmacêutica, por exemplo, declarou: "Vivi quatro anos internada num hospital, dando plantão diariamente, para poder economizar e comprar o apartamento". Quanto aos inquilinos, ou pagam um aluguel de NCr\$100,00 a NCr\$ 150,00 , pois vivem há muito tempo no prédio, ou pagam um aluguel mais baixo do que o aluguel médio de Copacabana. Constatamos ainda que a maioria dos entrevistados não tinha empregada doméstica (apenas um declarou ter empregada). Isto mostra que a renda desses indivíduos não dá para tal "luxo" (como disse uma das moradoras). Além disso, o gasto com transporte é pequeno, pois Copacabana fica relativamente perto dos locais de trabalho. Esses dados iniciais já podem nos indicar que os moradores do 200 localizam-se nas camadas média e média inferior da sociedade.

Passando para um outro nível de análise, verificamos que a maioria dos moradores não tem condição de sair do 200. Estão, de certa forma, encurralados entre o desejo de participar da sociedade de consumo e a precariedade de suas habitações. Esses indivíduos que têm uma ocupação mais ou menos estável no sistema, uma renda superior a de um trabalhador especializado, e geralmente superior àquela que tinham em seus locais de origem, passam a consumir bens (mesmo que estes sejam limitados) da sociedade de consumo: televisão, rádio, vitrola, geladeira, vestuário, diversões etc. A partir de um dado momento, já não podem prescindir destes recursos. Por outro lado, a necessidade de consumir novos bens vai limitar o montante de renda gasto na habitação. Portanto, a opção seria participar da sociedade de consumo e morar em condições precárias, ou não participar (ou participar menos) e morar melhor. É óbvio que a habitação de certa forma faz parte deste sistema de consumo, mas não isoladamente, e sim fazendo parte de uma rede de bens. Assim, usufruir continuamente de um mínimo destes bens implica para o morador do 200 sacrificar-se em termos de habitação - espaço, oxigênio, contato com a natureza e mesmo higiene.

Ao lado disso é preciso frisar o fato de que na medida em que as camadas médias da sociedade caracterizam-se sobretudo por sua instabilidade, a maior ou menor 
possibilidade de sair do "impasse" estará ligada, evidentemente, à problemática geral do processo de desenvolvimento da sociedade brasileira como um todo.

Embora seja difícil determinar com rigor a posição dos moradores do prédio na estratificação social, acreditamos que, de um modo geral, podem ser enquadrados nas camadas média e média inferior da sociedade. É importante chamar a atenção para a heterogeneidade dos moradores, não só em relação à renda, mas também ao status. É óbvio que estas diferenças são o reflexo da variação em nível educacional, origem, ocupação, ser ou não proprietário, entre outros.

\section{Prostituição e outros problemas}

Esta é a parte de Copacabana onde é mais evidente o movimento de prostituição. 0 grande número de hotéis, boates, "inferninhos" e de turistas nacionais e estrangeiros explica, pelo menos em parte, o fato.

Praticamente todas as pessoas de fora do prédio com quem conversamos sobre o Barata Ribeiro 200 consideram-no um imenso bordel. As piscadelas de olho, os olhares maliciosos e as piadas "picantes" acompanham as referências ao prédio. As próprias autoridades com quem tivemos contato - o delegado de Copacabana e o fiscal da Secretaria de Justiça - consideram o prédio uma "chaga", em que a prostituição é o problema central.

As nossas entrevistas, dentro e fora do prédio, não deixam dúvida de que desde o "habite-se" pode ser registrada a presença de prostitutas ali residindo. A atitude da maioria esmagadora dos moradores entrevistados em relação ao problema é de procurar minimizá-lo, ao contrário das pessoas de fora (vizinhos, autoridades etc.). Uns dizem que nunca viram nada. Outros dizem que no andar em que vivem não há nada de anormal. Finalmente, há os que fazem questão de ressaltar que no seu "canto" nada acontece de errado. Ao lado dos que negam pura e simplesmente, existem alguns que admitem que há algum tempo atrás o prédio tinha muitos problemas, mas que agora está tudo bem, trata-se de um edifício familiar etc., etc. Raros dos 29 moradores entrevistados admitiram ali a presença, atualmente, de prostitutas. Uma senhora viúva, farmacêutica aposentada, foi a única pessoa que falou com real desinibição sobre o 200. Enfatizou a existência não só da prostituição, como também do homossexualismo, do tráfico de entorpecentes, de escândalos e brigas. Explicou as reticências e as esquivas dos outros moradores dizendo que "eles têm medo".

Mais tarde viemos a saber que existiam recomendações do delegado de Copacabana, transmitidas através do síndico, para que os moradores não comentassem e falassem dos problemas do prédio, pois "isto só podia piorar as coisas". o próprio delegado confirmaria isto. Referindo-se ao problema da prostituição no 200 , disse que se ele tivesse sido cortado desde o início com uma enérgica intervenção das autoridades, o prédio não teria se transformado "num dos maiores problemas policiais de Copacabana". Continuou dizendo que, na sua opinião, houve negligência das autoridades da época, não impedindo a proliferação dos problemas. Afirmou procurar proteger os vizinhos do prédio das desordens promovidas pelas prostitutas. Quanto aos moradores do 200 propriamente, explicou que estes já estavam acostumados e que ele não dispunha de meios para "limpar o prédio", expulsando os maus elementos. Acentuou faltar-lhe cobertura jurídica para tomar tal providência, mas que regularmente promove batidas na rua perto do 200 , prendendo as 
prostitutas, mas que estas acabam sendo soltas, pois "isto não é crime". Disse não ver solução para o problema do prédio e que se deve tentar formar uma espécie de "cordão sanitário" à sua volta para proteger a vizinhança.

Apesar de todo o alarido, calculamos em cerca de 50 o número de prostitutas residentes no prédio, ocupando em média um apartamento por andar, ou seja, 2,5\% dos moradores do prédio. Estes dados foram obtidos através das poucas entrevistas em que se pôde falar do problema com maior liberdade. Quem são os 1.950 moradores restantes? Serão todos marginais? o que pudemos depreender é que existe no edifício um número de homossexuais comparável ao das prostitutas, o que totalizaria cerca de 100 pessoas $5 \%$ da população do 200. Ainda assim seria uma proporção muito reduzida para justificar o fato de o prédio ser costumeiramente encarado como um "bordel" ou um "problema insolúvel". Um dos pontos que acentuam a turbulência real do 200 é o que poderíamos chamar de sua "população flutuante" - os frequentadores dos apartamentos das prostitutas e dos homossexuais, fundamentalmente. Ao que parece, algumas dessas pessoas têm ligação com o tráfico de maconha, não sendo poucos os escândalos relacionados com indivíduos sob o seu efeito. Além disso, alguns dos apartamentos são utilizados como garçonières, não sendo habitados normalmente. Dizem ser utilizados por homens de negócios, “pessoas graúdas”... Embora não possamos precisar o seu número, ele não parece ser insignificante. Ainda assim, não chegaria a ser alarmante.

o fato é que o número de "maus elementos" mostra-se exíguo se comparado com a quantidade de incidentes ocorridos no prédio. Pelo que verificamos na delegacia de Copacabana, é realmente assustador o número de casos registrados no 200. Apesar das declarações da autoridade policial de que as prostitutas são as responsáveis pelos tumultos, examinando os últimos casos registrados no prédio, nada havia relacionado com o problema de prostituição. Tratava-se de incidentes entre vizinhos (barulhos, crianças etc.), ou entre marido e mulher - brigas domésticas que assumiam proporções um tanto excessivas. Examinaremos isto adiante.

\section{Ideologia}

Partindo deste problema - como os moradores encaram a turbulência do prédio verificamos algumas características interessantes de sua ideologia.

Num primeiro nível, os moradores entrevistados, praticamente sem exceção, negam a existência de problemas no 200. Em um segundo nível, admitem a existência no passado de algo ("agora não há mais nada"; "é tranquilo") e, quando admitem, enfatizam o papel das prostitutas e, em menor grau, dos homossexuais. É interessante que a maioria não dá nome, utilizando uma linguagem meio fabular - "essa gente", "gente que não presta" etc. Em um terceiro nível, revelam-se dados extremamente curiosos. Os entrevistados começam a contar a vida do prédio e passam a narrar os incidentes que presenciaram. Pouco a pouco eles vão "se contando" nessas narrativas. Verificamos que os próprios entrevistados que, a princípio, se apresentaram como absolutamente distantes da turbulência local, participaram de brigas, incidentes, que chamaram a polícia. Passam a ser personagens desses incidentes. É importante frisar que, dos 29 entrevistados, 18 contaram casos em que tinham sido participantes ativos. Apenas uma minoria destes casos narrados envolviam problemas de prostitutas ou homossexuais. 
Eram fundamentalmente brigas de vizinho. Daremos um exemplo de uma dessas historinhas narradas por uma dona de casa, esposa de um funcionário público:

Sempre detestei barulho, sempre respeito os vizinhos. Não deixo rádio ligado alto, não deixo meus filhos fazerem barulho. Mas tem uma gentinha por aí que parece que veio da favela. Cantam, brigam, xingam. Não têm hora para fazer barulho. Uma dona aí de cima sempre deixava o rádio aos berros até tarde da noite. Um dia, não aguentei. Fui para a janela e pedi para ela diminuir. Ela respondeu aos palavrões. Não tive dúvida, chamei a polícia. Foi ótimo. Ela ficou quieta uns tempos, mas agora já está começando a se engraçar de novo. Qualquer dia vou ter que chamar a polícia.

Perguntada por que não falava com o síndico, respondeu: "Com essa gente tem que chamar a polícia". No caso, "essa gente" era uma outra dona de casa casada com um médico. De um modo geral, essas historinhas têm três elementos - dois vizinhos contendores e a polícia. Ocasionalmente, outros vizinhos e o síndico podem participar dos tumultos, mas a regra geral é esta.

É óbvio, portanto, que existe uma tentativa de mascarar a realidade que, acreditamos, ser em parte consciente e em parte inconsciente. Há a tentativa também de manter uma imagem e uma autoimagem de acordo com certas regras de bom comportamento. Embora não tenhamos elementos suficientes para comprovar o aspecto inconsciente do mecanismo, a convicção dos entrevistados e um certo tipo de racionalização comum aos moradores são preciosos indicadores.

Outro aspecto importante da ideologia dos entrevistados é o tipo de justificativa para a sua permanência no prédio. Indiscutivelmente está ligado ao que acabamos de abordar. Primeiro amenizam os problemas locais - "não é tanto assim", "qualquer lugar com muita gente tem problemas", "nunca vi nada", "estou muito satisfeita". Dizem que o tamanho do apartamento é bom, que o ponto tem bons comércio e transporte, cinema, diversões, praia etc. Em resumo, o que nos parece importante é que existe certa admissão tácita de que há um preço para morar na Zona Sul, especialmente em Copacabana. No 200, os aluguéis são mais baratos - isto é uma vantagem. Há "recursos". Ora, na medida em que verificamos que boa parte dos entrevistados veio do subúrbio ou de cidades do interior fica patente que para estes indivíduos morar no 200 significa uma melhoria. Um ou outro falou nostalgicamente da casa onde morava, com muitos quartos, quintal, mangueiras... Mas estes foram exceções. Ou a maioria dos moradores do 200 não vivia nestas condições nos lugares de onde vieram ou, se viviam (os que viviam), acharam que valeu a pena perder espaço e mangueiras para morar em Copacabana. É importante frisar que poucas pessoas (vindas do interior) falavam vagamente em maiores oportunidades de emprego. Quando se insistia em saber a relação entre maior oportunidade de empregos e morar em Copacabana (por que não Méier, Tijuca, Botafogo ou outros?), voltavam a falar em mais recursos, "divertimentos" e outros. É importante chamar a atenção também para o fato de que vários entrevistados têm certa consciência de que morar no 200 pode torná-los objetos de uma discriminação social. Por isto mesmo se defendem com unhas e dentes, dando exemplos de edifícios muito piores e sempre dizendo que a coisa não era tão grave, que havia exageros...

Por outro lado, conversando com vizinhos do 200, sentimos realmente sinais de discriminação em relação aos moradores do prédio. Falam "nessas vagabundas" e nessa gentinha. Deviam "acabar com o prédio, expulsar esse pessoal". As autoridades que entrevistamos não revelaram atitude muito diferente. $O$ problema é definido como policial. Dizem (especificamente a autoridade policial) que o edifício "não tem jeito, 
mas é preciso mantê-lo sob controle para não prejudicar os vizinhos". É a teoria do cordão sanitário que foi desenvolvida. $O$ fato é que o 200 realmente vive sob controle. Há épocas em que o síndico do prédio tem entrevista semanal com o delegado de Copacabana. Este determina uma série de coisas que são transmitidas pelo síndico aos moradores. Sentimos especificamente isto, como já foi dito, diante da determinação do delegado de que os moradores não falassem do prédio, pois isto "só podia piorar". A presença da polícia no 200 é rotina, não só para atender aos constantes chamados, mas também para "controlar o ambiente". Os moradores estão acostumados com isso e já encaram como parte das regras do jogo.

Soubemos, através de um informante, que já houve problema de "subversão" no prédio. Com a descoberta de "ninhos" de subversivos em apartamentos da Zona Sul (especialmente em grandes edifícios), aumentou ainda mais a vigilância da polícia. Os próprios moradores justificam a presença da polícia dizendo que para lidar com certo tipo de gente que mora no prédio só mesmo a polícia. Eles próprios, muitas vezes, tomam a iniciativa de chamar a polícia para intervir nos incidentes mais insignificantes, como briga de criança, barulho ou outros. Além disso, impressiona fortemente a falta de solidariedade entre os moradores. Todos, sem exceção, dizem que não gostam de se meter com vizinhos. Percebemos que alguns se frequentam, mas constituem exceção. $O$ normal é não manter nenhum contato mais íntimo. Os que têm telefone fingem que não têm para que os vizinhos não explorem. Há um clima de tensão constante, de desconfiança.

Quando surgem problemas, não há nenhuma tentativa de diálogo - imediatamente chama-se a polícia ou então se parte para conflitos com ofensas e, muitas vezes, agressões físicas. Aí mesmo é que a polícia aparece. O síndico não consegue coordenar nada. Queixou-se amargamente de que ninguém colabora. Parece ser uma pessoa ao mesmo tempo hostilizada e temida. Isto porque ele é o intermediário entre os moradores do prédio e a autoridade policial. Há constante mudança de síndicos, que são em geral acusados de corrupção. Uns renunciam, outros são demitidos pelo conselho de proprietários, mas sempre o síndico funciona tutelado pelo delegado de Copacabana em maior ou menor grau. Isto também é aceito de maneira tácita. É óbvio o clima de repressão.

Pelo que vimos, de um modo geral, o que os entrevistados fazem nas horas de lazer é, fundamentalmente, ver televisão. Ir à praia ou ao cinema não aparece com muita frequência. As crianças, quando não estão na escola, costumam brincar nos enormes corredores do prédio ou então assistem à televisão. É claro que parece que vão mais à praia do que os adultos. É interessante o caso de uma entrevistada que justificou sua ida para Copacabana falando em "recursos" e "divertimentos" e que mais adiante disse que ficava sempre em casa vendo televisão: "Pra que sair? Televisão é tão bom".

Em resumo, essas pessoas só podem viver em Copacabana em edifícios como o 200, onde os aluguéis são mais baixos. Não abrem mão de estar perto dos bens oferecidos pela sociedade urbana industrial, mesmo que os utilizem de modo muito limitado. Em termos de status, sentem-se em posição mais elevada vivendo em um prédio em Copacabana que tem fama de bordel, num apartamento mínimo do que num apartamento ou numa casa da Zona Norte ou no subúrbio com mais espaço, terreno etc. Verificamos que apenas uma percentagem pequena trabalha perto do prédio, não havendo, portanto, a explicação de proximidade de residência e local de trabalho. Estranho que possa parecer a princípio, o fato é que, para a maioria dos entrevistados, 
morar no 200 significa "subir na escala social" e participar mais integralmente das "delícias da sociedade de consumo". O impasse é que se alguns começam a se sentir emparedados no prédio, pouquíssimos têm saída. Ter saída significaria mudar-se para um prédio melhor em Copacabana, mas a renda é insuficiente. Voltar para o subúrbio ou para o interior é praticamente inaceitável. Portanto, os poucos (dos que entrevistamos) que demonstram maior insatisfação não têm perspectiva de sair e vão ficando cada vez mais angustiados e tensos.

\section{Conclusões}

Nossa amostragem foi muito limitada, o que evidentemente relativiza muitas de nossas hipóteses. Por outro lado, procuramos cotejar as entrevistas dos moradores com informações de pessoas de fora do prédio - desde vizinhos até autoridades. Ficamos especialmente interessados em perceber a imagem pública do 200 no bairro e na cidade em geral.

Parece-nos que o Barata Ribeiro 200 é um caso limite de um tipo de situação muito encontrada na Zona Sul da cidade do Rio de Janeiro. Há dezenas de edifícios gigantescos com apartamentos mínimos onde, como disse um morador do 200, "as pessoas não vivem, se escondem". Estes prédios são frutos de uma especulação imobiliária desenfreada e de todo um processo global que transcende os limites de um simples problema de planejamento local. ${ }^{3}$

Observamos outros prédios além do 200 (mais superficialmente), e neles encontramos uma série de características que muitos pensam ser exclusivas do 200. O que acontece é que neste famoso prédio os problemas atingem uma extensão e uma complexidade maiores devido às suas dimensões de fato excessivas e haver uma absoluta ausência de "racionalidade". Insistimos, portanto, que a situação do 200 só pode ser compreendia como resultado de um processo com variáveis nos mais diversos níveis. Migrações, estratificação social, delinquência, discriminação, repressão são alguns dos temas que poderiam ser aprofundados partindo do 200 . No entanto, devido às nossas limitações de tempo e pessoal, tivemos que manter esta visão mais superficial e impressionista. Acreditamos que, apesar disto, alguns problemas interessantes possam ter sido indicados.

\section{Comentários de Anthony Leeds}

This is descriptively an excellent paper based on a rather difficult field work situation. Its lack of some sort of theoretical orientation is reflected in its lack of a title - why the study? What was it supposed to show? Actually this is my main complaint about the paper - they could have done a much more interesting job relating the paper to a number of issues which appeared in the classroom discussions. The absence of significant footnotes is a further reflection of the limitation of the paper. It is obvious that the casal antropológico is very talented and is (or are) able field workers. I knew from class work that they are able thinkers and understanders too. 


\title{
O Barata Ribeiro 200: um pós-escrito
}

\author{
Yvonne Maggie
}

IFCS/UFRJ

41 Este texto é um trabalho de curso que eu e Gilberto Velho fizemos para Anthony Leeds, em 1970. Para situar o escrito a partir de minha perspectiva, tenho que tecer alguns comentários, fazer uma certa arqueologia dessa pesquisa. $\mathrm{O}$ tempo apaga muitas coisas e a memória trai, mas os esquecimentos e as lembranças são a matéria do pensamento e neles se pode entender muito daquilo que é dito.

Gilberto Velho e eu nos conhecemos na Faculdade Nacional de Filosofia (FNFi), no curso de Ciências Sociais, em 1965, um pouco depois do golpe militar, e nos formamos em dezembro de 1968. Em julho desse ano nos casamos e fomos morar em um prédio de apartamentos conjugados - o edifício "Estrela" - que seria mais tarde objeto da dissertação de mestrado de Gilberto.

Por injunções do destino, apesar de sermos indicados por Marina São Paulo de Vasconcelos, cassada pelo golpe de 1968, fomos contratados como docentes pela UFRJ e começamos a lecionar no IFCS em março de 1969. O mestrado em Antropologia Social do Museu Nacional havia sido criado no início de 1968. Em julho de 1969, nos tornamos alunos de pós-graduação sem ter que fazer nenhuma prova. Não havia outros candidatos.

Anthony Leeds foi lecionar no mestrado a convite de Roberto Cardoso, e ofereceu um curso sobre Antropologia Urbana, um dos mais ricos e inovadores daquele ano. Éramos poucos alunos, mas me lembro bem de Luiz Antonio Machado da Silva e do arquiteto Carlos Nelson Ferreira dos Santos, autor, mais tarde, do belo livro A cidade como um jogo de cartas (http://goo.gl/kHSQqH), entre outros.

As aulas do Tony Leeds eram dadas em uma das salas arejadas que dão para o jardim dos fundos do Museu Nacional. Foram discussões surpreendentes porque a antropologia urbana de Leeds era extremamente rica e tinha uma abordagem pouco comum para a época. Desorganizadamente organizadas, as aulas introduziram questões que foram como um mapa para as nossas pesquisas na cidade e para os futuros trabalhos do Gilberto. Tony insistia que fizéssemos pesquisa de campo e nos estimulava a pensar a cidade e, em especial, o Rio de Janeiro, a nossa cidade. Lemos uma bibliografia inusitada e o texto que mais me marcou foi "A situação da classe trabalhadora na Inglaterra", de Friedrich Engels. Tony nos mostrou como a descrição de Engels das cidades inglesas foi feita com o cuidado de um antropólogo em uma aldeia. Fontes primárias foram utilizadas e a própria observação do autor era determinante e impecável. Foi nesse curso que Gilberto teve a ideia de pesquisar um prédio de conjugados e a visão de mundo das camadas médias em uma cidade brasileira. A amizade com Tony nos levaria também ao Texas no ano seguinte.

Como contei acima, morávamos no edifício Estrela, um prédio de conjugados em Copacabana. Gilberto vivia perguntando aos vizinhos porque gostavam tanto daquele lugar. Era uma pergunta sociológica, é claro, mas, na minha percepção, revelava também a angústia de Gilberto de ter de viver naquele lugar de "má fama". Antes de se mudar, Gilberto morava com a família no mesmo bairro, mas em um bom apartamento 
de três quartos. Um imóvel confortável e que dava status. Mudar-se para um conjugado produziu nele uma espécie de sofrimento social, apesar das alegrias do casamento.

Eu não sentia assim. Para mim, morar naquele apartamento cheio de problemas, mas arrumado com muito esmero por mim e com a ajuda financeira de um irmão, foi um alívio. Eu vinha de uma casa enorme no Leblon, ao lado da praia. Tinha vivido minha vida inteira com muitos irmãos e fui a irmã mais velha (sem ser), que geria a vida doméstica desde que ficamos órfãos muito cedo. Fui a última a sair da casa do Leblon. Deixei-a com dor, mas com a sensação de que era preciso mudar e viver a minha vida. Nunca pensei que morar em um conjugado fosse uma "decadência".

Pessoas vivem histórias semelhantes e podem ter impressões muito diferentes sobre elas. No meu caso, o apartamento do edifício Estrela era uma bênção. Uma alegria compartilhada com a pessoa que eu havia escolhido para viver o resto da minha vida. Um alívio.

49 Foi essa sensação de estranhar as perguntas de Gilberto aos vizinhos que me fez ver que eu não me importava com o que eles pensavam. Gilberto era fascinado pelos outros moradores e um pouco irritado de vê-los felizes ali. Suas perguntas eram uma forma de entender também a sua própria subjetividade. Por que não gostava de morar ali?

50 A pesquisa no "Barata Ribeiro 200" foi feita por sugestão de Tony, que insistiu para que Gilberto tivesse uma experiência fora de um ambiente que já conhecia. Lembro-me bem do dia em que fomos pela primeira vez no prédio. Tinha uma portaria escura e corredores muito mais estreitos e longos do que os do edifício em que morávamos. Lembro-me claramente das entrevistas naqueles apartamentos cheios de móveis antigos, pesados, de madeira escura. Mesas que ocupavam quase todo o conjugado e armários que, em alguns casos, serviam de divisórias. Havia muita gente pelos corredores. Eu me recordo de uma moça que, ao ser perguntada se gostava do lugar, respondeu: "Eu não moro, eu me escondo aqui". A maioria dizia que gostava de morar ali pelos motivos que estão descritos no trabalho. Foram essas respostas um tanto contraditórias que nos levaram a pensar sobre a mudança para Copacabana como símbolo de status e também sobre a experiência de não conseguir sair de lá depois de se ter acostumado com a facilidade de acesso aos bens de consumo e aos serviços do bairro.

51 A descrição do síndico do Barata Ribeiro parece hoje meio inverossímil, mas a pesquisa foi feita em 1970 e estávamos em plena ditadura militar no Brasil. Não mencionamos isso no trabalho, mas a repressão se utilizava desses porteiros para vigiar e punir os cidadãos. No prédio em que moramos, houve inclusive um assassinato em que a polícia jogou um jovem militante pela janela.

52 Só hoje percebo como a minha participação naquele início de vida acadêmica do Gilberto foi importante para nós dois. Aprendi a fazer pesquisa junto com ele e o "Barata Ribeiro 200" foi nosso primeiro passo. Viver no edifício Estrela não teve o mesmo impacto na minha vida que teve na do Gilberto, eu suponho. Para a dissertação de mestrado, quis me afastar do familiar e do próximo. Decidi estudar um terreiro de umbanda, longe da tradição da minha família católica. Foi uma pesquisa que exigiu um esforço enorme de sair da minha vida cotidiana.

53 Aquele curso do Tony foi o estopim para uma antropologia urbana menos sociológica e influenciada pelos modelos de classe social. As poucas referências bibliográficas, além do trabalho do próprio Leeds, eram de sociólogos que estudaram estratificação social e 
hierarquia social, ou as formas socialmente construídas de pensar a posição social. Não havia naquela altura a influência da Escola de Chicago e de Howard S. Becker na obra de Gilberto e, muito menos, a influência da antropologia social inglesa, de Victor Turner e de Mary Douglas, nas minhas pesquisas.

Relendo esse texto, 43 anos depois, fiquei com a sensação de que ali estava a origem da dissertação que foi defendida pelo Gilberto no ano seguinte. Sem a pressão de Tony para que fôssemos ao "Barata Ribeiro 200", talvez o insight d' A Utopia Urbana tivesse sido mais difícil. Falar sobre esse trabalho me traz a percepção de que fizemos uma pesquisa muito pioneira. Nela estava o embrião não só d'A Utopia Urbana, mas também dos trabalhos que se seguiram, nos quais Gilberto mergulhou no ethos, nas emoções e no mundo dos sentimentos de pessoas de camadas médias urbanas. $\mathrm{O}$ esforço de relativizar sua experiência pessoal fez com que ele construísse uma antropologia urbana diferente, uma antropologia na cidade e da cidade.

\section{BIBLIOGRAFIA}

GERMANI, Gino. 1969. "Desenvolvimento, Econômico, Urbanização e Estratificação Social”. Coleção Textos Básicos de Ciências Sociais. Rio de Janeiro: Zahar Editores.

PEREIRA, Luiz. 1969. “Urbanização e Subdesenvolvimento”. Coleção Textos Básicos de Ciências Sociais. Rio de Janeiro: Zahar Editores.

STAVENHAGEN, Rodolfo. 1966. "Estratificação Social e Estrutura de Classe”. Coleção Textos Básicos de Ciências Sociais. Rio de Janeiro: Zahar Editores.

\section{NOTAS}

1. $O$ artigo original não possuía titulo, como evidenciado na avaliação de Anthony Leeds. $O$ título foi inserido para esta publicação, com o consentimento de Yvonne Maggie.

2. NR: Registro do antigo "cruzeiro novo", moeda já fora de circulação no Brasil.

3. Ver Leeds, Anthony, 1969. (Esta referência constava na bibliografia original mas sem título e, portanto, foi retirada da bibliografia nesta publicação)

\section{RESUMOS}

Trata-se de uma etnografia da vida dos moradores de um prédio em Copacabana. Realizado em 1970 como trabalho final do curso Antropologia urbana curso Antropologia urbana no Programa de Pós-Graduação em Antropologia social do Museu Nacional da UFRJ. O curso foi ministrado pelo 
professor Anthony Leeds. $\mathrm{O}$ artigo descreve a vida e as representações dos moradores do edifício Barata Ribeiro 200 e aponta para as principais hipóteses e conclusões que serão desenvolvidas por Gilberto Velho no seu clássico A utopia urbana e na sua obra posterior. Gilberto Velho e Yvonne Maggie, na época casados, fizeram um trabalho de campo pioneiro ao vivenciarem o dia a dia dos moradores do prédio de apartamentos conjugados, ao mesmo tempo em que residiam em um edifício semelhante em outra rua do mesmo bairro. 0 artigo conta com um pós-escrito de 2013 de Yvonne Maggie e ainda traz as observações do professor Anthony Leeds ao trabalho e ao casal de jovens antropólogos de 1970.

The article consists of an ethnographic account of the inhabitants of a building in Copacabana. It was written as a final paper for the course in Urban Anthopology taught by Professor Anthony Leeds, at the Graduate Program in Social Anthropology, Museu Nacional, UFRJ. The article describes the life and representations of the people living in the building Barata Ribeiro 200, and points to the main hipotheses and conclusions which were developped by Gilberto Velho in his classic book A Utopia Urbana, as well as his later work. Gilberto Velho and Yvonne Maggie, married at the time, carried out pioneering fieldwork, sharing the everyday lives of the building made up of small studio apartments (conjugados), while living in a similar building on another street in the same neighborhood. The article is accompanied by a post-scriptum written in 2013 by Yvonne Maggie, as well as Professor Anthony Leeds' comments to the young anthropological couple, written in 1970.

\section{ÍNDICE}

Keywords: urban anthropology, Copacabana, Barata Ribeiro 200, social hierarchy and status, ethnography

Palavras-chave: antropologia urbana, Copacabana, Barata Ribeiro 200, hierarquia social e status, etnografia

\section{AUTORES}

\section{GILBERTO VELHO}

MN/UFRJ Gilberto Velho (1945-2012) foi professor titular e decano do Departamento de Antropologia do Museu Nacional da UFRJ. Pioneiro da Antropologia Urbana no Brasil, com diversos livros publicados, entre os quais A utopia urbana (1973), Desvio e divergência (1974), Individualismo e cultura (1981), Subjetividade e sociedade (1986), Projeto e metamorfose (1994), Nobres \& Anjos (1998) e Antropologia urbana (2002).

\section{YVONNE MAGGIE}

IFCS/UFRJ Yvonne Maggie é professora titular do Departamento de Antropologia Cultural do Instituto de Filosofia e Ciências Sociais da Universidade Federal do Rio de Janeiro. Mestre e Doutora em Antropologia Social pela UFRJ, com especialização em Antropologia Urbana e das Sociedades Complexas na Universidade do Texas, em Austin. É Comendadora da Ordem Nacional do Mérito Científico (2008) e bolsista Cientista do Nosso Estado da Faperj desde 2010. Autora dos livros Guerra de orixá: um estudo de ritual e conflito (1975 [2001]), Medo do feitiço: relações entre magia e poder no Brasil (1992) e, em coautoria com Claudia Barcelos Rezende, Raça como retórica: a construção da diferença (2002). Contato: yvonnemaggie@gmail.com 